\title{
CAN THE TRADITIONAL ARTS SURVIVE, AND SHOULD THEY?
}

\section{Philip Yampolsky}

\section{Definition}

What are we talking about when we use this term "traditional" in Indonesia? Let me offer just a quick and simple definition here, so you know at least what I have in mind. I will phrase it (and most of this talk) in terms of music, because that is the art I know best, but I believe the essence of what I say could be applied to other traditional arts as well. I imagine a continuum, at one end (the "wholly traditional" end) of which is music that shows no obvious foreign (extra-Indonesian) influence in its musical idiom; at the other end is music that is wholly foreign in idiom. For my purposes today, any music that registers at or near the traditional end may be considered traditional. At the other end of the scale would be music in the European harmonized idioms (pop Indonesia, patriotic songs, church songs) or music in the mixed Middle Eastern/Indian/Western idioms of dangdut, orkes gambus, and qasidah moderen. ${ }^{2}$ In between would be the musics in "hybrid" idioms-kroncong, for example, or tanjidor.

A more complicated, but perhaps more useful, picture could present two continua. One would be the one just described; the second would have the same poles, but the domain would be not the music's idiom but its aesthetic. (Musics would be positioned on this continuum according to the extent, for example, to which they have been packaged in accordance with European/American norms of duration, virtuoso performance, attractive young performers, sharp beginnings and endings, predominance of singers over instrumentalists, etc.) But I will not bring this aesthetic domain into the discussion here.

${ }^{1}$ Talk given at the Seminar on the Position of Traditional Arts in the Twenty-First Century, Centre Culturel Français, Jakarta, May 4-7, 2000.

2 Brief definitions of the genres of Indonesian music mentioned in this talk appear in a glossary at the end. 


\section{The Situation Today}

Over the ten years from 1990-1999, I was fortunate in being able to work with many Indonesian colleagues on a project to produce a series of recordings surveying the music of Indonesia. ${ }^{3}$ This work enabled its researchers to travel to many parts of Indonesia, and as a result I can give a sort of status report on traditional music in the 1990s.

In Jakarta, or abroad, we tend to get an overly simple picture of the state of traditional music in Indonesia: it's dying inexorably, or it's already dead, there's nothing left except in one or two exceptional places like Bali and Central Java, and it's on its way out there too. What we found in the course of the recording project suggests a more complicated and fundamentally a more hopeful picture.

Even quite close to Jakarta-in Tangerang or Bekasi, say-there are frequent performances of traditional arts in traditional contexts (that is, not on stage for elite audiences or for tourists, and not on television for audiences sitting at home). There is no doubt that such performances are fewer than they were twenty years ago, and vastly fewer than, say, seventy years ago. But they are still there. There is also no doubt that the number of different kinds of performances is smaller than it was in the past. In many parts of the country, the traditional performing arts have been to some extent displaced by television and movies, by pop and dangdut bands, and by karaoke. But in most of the places we visited, there were still active performers of traditional genres. In rural areas where televisions and pop bands are few and local languages are strong, traditional genres are still the dominant form of entertainment.

What is true to say, I think, is that in most places-though again, not in the most rural areas-the performers and their most enthusiastic audiences are largely middleaged or older. Younger people are, for the most part, not interested. But here too it depends where you are. In Nias, when we recorded the kind of singing called hoho, most of the singers were middle-aged, but the soloist and song-leader was seventeen years old. The tertiary-level arts institutions in Java, Bali, and West Sumatra are full of students learning traditional performing arts. And in communities in eastern Indonesia-in Flores, for example-young people take part enthusiastically in communal singing and dancing. For another example: if you ask most people, they will tell you that the art of bantering through spontaneous or memorized verses is lost; but we often encountered young people trading verses in the course of our research.

If traditional music were as endangered as people say, our teams would not have been able to fill twenty CDs and nearly four hundred hours of field tapes with recordings. But still, for all that, there are few places in Indonesia where you could say that traditional music thrives. Very few artists can live comfortably just from music.

\footnotetext{
${ }^{3}$ The survey, consisting of twenty compact discs with extensive commentary, is published in the United States by Smithsonian Folkways Recordings, under the title Music of Indonesia. An Indonesian-language edition, called Seri Musik Indonesia, is being published in Indonesia by the Society for Indonesian Performing Arts (Masyarakat Seni Pertunjukan Indonesia, or MSPI); the first ten volumes are now available. The entire project was supported by a grant from the Ford Foundation. [Editor's Note: Please see the review of Music of Indonesia in this issue: Jan Mrázek, "A Musical Picture of Indonesia."]
} 
And, as I say, performers and audiences are aging, while young people are in general attracted to more urban and "contemporary" genres.

Now, according to Indonesia's Central Bureau of Statistics, 44 percent of the population of Indonesia is under the age of twenty, and 61 percent is under the age of thirty. The older constituency for traditional music is already a minority and is, of course, shrinking, and if young people are not interested, then quite rapidly its supporters will simply die out. And without an audience or performers, of course the music itself will also die.

\section{Can?}

I said earlier that the recording project results in a "fundamentally hopeful" picture. What is hopeful is that, contrary to many reports and many predictions, the traditional arts are not dead in Indonesia. But they do need help.

Can the traditional arts be helped? Should they be helped-or should we instead consign traditional music to the market and let it die if it has no buyers? I will talk briefly about whether anything can be done, but my main concern today is to offer some arguments for why we should care in the first place.

Well, can anything be done to strengthen traditional music? Notice that I don't say "can anything be done to preserve traditional music." I don't believe that anyone can preserve music or culture for anyone else, not in a meaningful sense. Preserve examples of it in a museum or in recordings, yes. But the only people who can sustain an art form or a cultural practice are the performers and their audiences. If they don't want it, it dies. If people are sick and tired of singing kroncong or dancing the minuet, then they stop and that's it. What outsiders (or concerned insiders) can do is try to find out why people don't want it, and see whether those reasons can be addressed. (Again, I will try to deal with the question of why we should bother to address those reasons later.)

What I conclude from the recording project's travels is that there were during the Suharto era, and there still are today, some very powerful voices in Indonesian society that sought and still seek to teach villagers not to want their traditional music. The government's culture programs very often have had the effect of telling villagers that their traditional arts are unsatisfactory as they are; they need to be improved (dibina, dikembangkan) before they will be acceptable to the government or to outsiders. Religious teachers and authorities demand that certain aspects of traditional musicor, in some cases, traditional music as a whole-be abandoned or purified. And, very pervasively, the ordinary everyday messages of newspapers, magazines, advertisements, radio, and television tell villagers that their way of life is backward, primitive, laughable. Is it any wonder that young people find little inducement to invest their energy and emotions in the music of their backward and ridiculous communities?

It is these pressures from the outside that we can address. Perhaps the single most crucial area in which to do that is education: we can provide schools with the materials for arts appreciation courses that recognize the dignity and value of traditional music. We can also influence the government, the media, and the tourist industry to treat traditional arts-and traditional society-more respectfully and sensitively. We can encourage outside interest in traditional arts—"outside" meaning 
outside the region, or even outside Indonesia-as a way of demonstrating to the inheritors of tradition the value that others place on it. The point of all of these efforts is to restore people's pride-young people's pride-in the arts of their region or their ethnic group.

But we must be realistic. Javanese gamelan or Minangkabau saluang will never again seem like the only "natural" music for Javanese or Minangkabau. The traditional arts will never regain the place they once had as the only arts that people knew. Television, radio, cassettes, and movies have reached all the cities of Indonesia, and it will not be long before they have reached every village and hamlet. Nor, reasonably, should we wish to prevent their spread: why should anyone be deprived of awareness of the world outside? Why should anyone be deprived of the great enjoyment and aesthetic pleasure the world's arts provide? What we can responsibly wish for as a minimum, I believe, is that the traditional arts be maintained in unbroken tradition by selfrenewing core groups of artists and appreciators, surviving as Scottish bagpipe music or Irish sean-nós singing or Javanese macapat singing or (on a larger scale) European "classical" music survive.

\section{Should? \#1}

So my answer to the first question is yes, the traditional arts can be helped. But should they? Why should we care what happens to arts that developed and flourished in the past, in feudal or peasant or nomadic societies, in conditions of insularity that are rapidly dissolving? If the young people want to dump those old arts and listen to rock and pop and jazz and dangdut, why should we preach about tembang Sunda and pakarena and gondang?

I want to offer two arguments in favor of intervening in defense of the traditional arts. Both arguments are instrumental: they show ways in which music is good for some end other than music, ways in which music symbolizes something else. These are by no means the only arguments I could adduce. For people who have gone deeply into music itself, a strong argument concerns the intrinsic value of music, the value of contemplation of abstract structures of sound-or, as Susanne Langer proposes, representations of the structures of feeling and experience. But such arguments only work for devotees; mine here are intended to speak to the unconvinced.

The first argument I propose concerns identity. Many people have had the experience of walking along or reading or talking and suddenly being stopped short by music-some music from their homeland, or from a bygone time, something they haven't heard in years, a sound that rivets them with emotion. What is it about such music that can stir such deep emotions, can move one even to tears? The best explanation, I believe, is that music serves most of us as a symbol of our identity and history, either as individuals or as members of a group. By performing or listening to Minangkabau music, for example, Minangkabau persons demonstrate-and also experience - their ethnic identity as a Minangkabau; when one hears the music one knew at an earlier time in life, one recalls the experiences and feelings of that time; by singing one's national anthem, one demonstrates one's citizenship. Music can symbolize other identities as well: one's religious affiliation, age group, place of origin, intellectual 
preoccupations, level or catholicity of taste, social status, or the social status one aspires to.

Not only is music a powerful symbol of ethnic identity (and all the other identities), it is an intangible one, one that can retain its power when other more tangible proofs-such as a society's autonomy, its land, its forests, its religious practices, its economy, its settlement patterns, its traditional modes of clothing-have been arrogated or crippled or outlawed by authorities or abandoned by the society itself. In the face of many pressures toward social integration and uniformity, intangible symbols such as music are sometimes all that people can retain of their identity.

If music symbolizes ethnic identity, then the existence in a society of music from many ethnic groups symbolizes the diversity of the society. (I am using the idea of the ethnic group here as shorthand for all sub-groups, whether based on ethnicity or some other affinity.) Now, people sometimes argue that ethnic groups need to lose their sense of separate identity in order to blend together into one nation. But social experiments in the denial of ethnic identity have been carried out at great human cost, and for the most part they seem to have failed. Despite years of enforced, superficial harmony, when the restraining power is removed, violence erupts.

Experience and logic suggest that people will always try to construct and assert individual and sub-group identities within the larger group identities offered by society. It seems then that what is needed is a form of society that accepts and celebrates plural, multiple identities - where one can be both Javanese or Dayak or Chinese and Indonesian; or, as in a notable anthropological study, simultaneously Punjabi and Mexican and American. ${ }^{4}$ Support for the spectrum of traditional music in a heterogeneous society like Indonesia would symbolize-but not only symbolize: it would also foster-the society's acceptance of its own diversity.

In this connection, I want to tell a story-a parable, actually. I once attended a wedding in Lampung, among the Melinting people, where adat dances (that is, dances appropriate to the traditional ceremony) were performed, to the accompaniment of a gong ensemble. In one of the adat dances, there was a row of six or seven women, all wearing beautiful Lampung textiles. As the music played, the women danced forward toward the bride and groom, then back to their original place. The whole line of women moved forward and back together, except for one woman, who danced in place the whole time-the rest of the women left her behind when they moved toward the bride and groom, and then rejoined her when they moved back. I asked some of the guests why the one dancer stayed in place-did she perhaps have a higher rank than the others? The guests replied oh no, it was simply that she was a woman from another ethnic group who had married into the community, and this is the way her people dance at weddings. 5

\footnotetext{
${ }^{4}$ Karen Isaksen Leonard, Making Ethnic Choices: California's Punjabi Mexican Americans (Philadelphia: Temple University Press, 1992).

5 After this talk was given, I spoke with a choreographer and dance specialist, R. Harry W. Jayaningrat, who lives in Lampung and is familiar with Melinting society. He believes that the information I was given at the wedding is incorrect: the woman who danced in place, he says, was probably a representative of the
} 
180 Philip Yampolsky

Ah. Different ethnic groups joining in the same celebration; different dances performed simultaneously for the same occasion. Unanimity without uniformity. Cultural pluralism.

\section{Should? \#2}

My second argument for why we should support traditional music and musicians is more complicated.

Music is, at the most fundamental level, a way of imposing structure on sound in time. At that level, it has no referential meaning: it is about just those three basic elements, sound, time, and structure. But imposing structure on materials is a basic activity of human life. We do it all the time: try to find patterns in the chaotic flow of sensation and experience, try to impose order, try to make sense of it. When we listen to music we hear an abstract, controlled representation of a central human activity.

Now most people grow up with some kind of music around them that they become used to. They learn the logic of that music without knowing they have done so, just as they learn the grammar of their native language without analysis. I'm not talking about musicians here, I'm talking about anyone with any liking for music. For such people, which means most of us, the music they grew up with is transparent: consciously or unconsciously, they know how it works. If they listen to a melody, they know when it's over; they can tell when it "doesn't sound right" because a singer or instrument has gone out of tune; if they try to dance to the music, they know how to find the beat without knowing how they know.

But if they try to listen to some other kind of music, from another culture, they are confronted with a different logic, a different way of structuring sound in time. And this, by simple extension, confronts them with the mystery of other people's experience: a different structuring of musical materials symbolizes-we are back to symbolism - a different way of making sense of life.

Let me give you some examples. (It's about time we got into some music!) Let's take a well-known Indonesian popular song from the time of the Revolution, Bunga Anggrek. ${ }^{6}$ (See Figure 1, below) Its structure-its logic-will seem transparent to everyone here, as it is the standard logic of the European popular idiom that swept the world in the twentieth century. It is in the diatonic scale and the simple tonal idiom that virtually everyone knows, but I want to concentrate on another aspect of the song: its phrase structure and phrase length. The thing to notice is that all of the phrases have the same form: they all start at the same point in the measure, and they all pause, resume, and end at the same points. Each phrase has the same length-four bars or measures of four beats each, in this notation. Thus the melody is made up of a string of structurally identical phrases; moreover, the phrases themselves are perfectly symmetrical, consisting of two structurally identical sub-parts. The overall melody

host's family, not of another ethnic group. If he is right, then what I have presented as a parable should be seen instead as a fable-but one that still offers an ideal picture of performance in a multicultural society.

${ }^{6}$ When sung with Dutch lyrics, this song is known as Als de orchideeën bloeien. The Indonesian text was composed by Ismail Marzuki, and the melody is frequently attributed to him as well. 
BUNGA ANGGREK
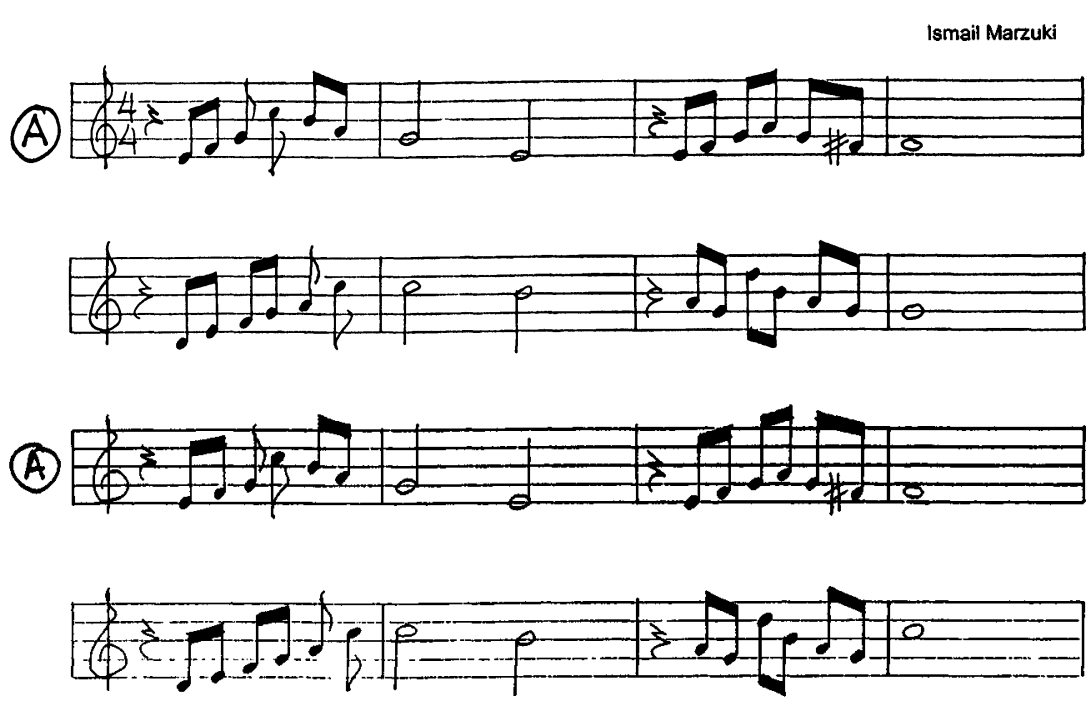

(B)
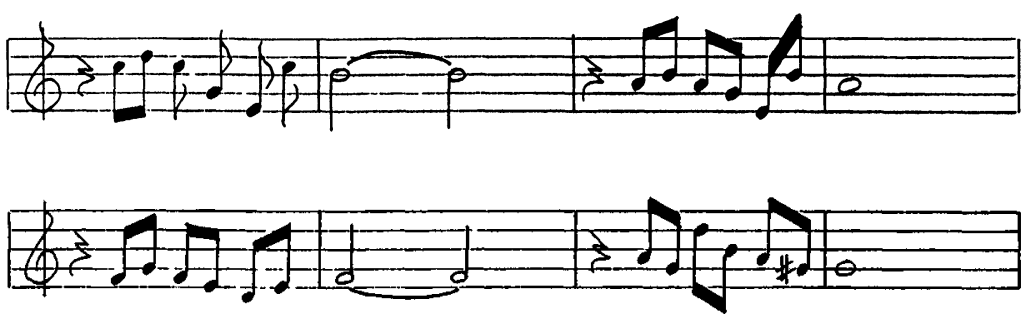

(A)
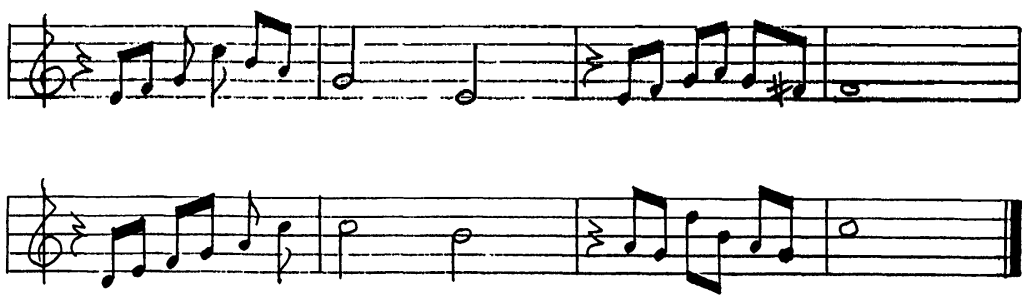

Figure 1

transcribed - P.Y.

carries out this concern with the repetition of identical elements: the first two phrases, which together we can call $A$, are stated once and then repeated; then two new phrases, structurally identical to the first pair, make a $B$ section; then we return to the original pair. The whole thirty-two-bar structure can be represented as A-A-B-A.

Now this is an extremely common structure in the standard European idiom of popular music (though admittedly not all popular songs are as rigidly regular as this one). We have all heard it thousands of times; we don't notice it; it makes perfect sense to us. But let me play you an example of a different approach to song structure. (Figure 2) In this choral song from Timor, ${ }^{7}$ the melody has none of the symmetry of

${ }^{7}$ Recorded in 1990 near Atambua by Margaret Kartomi and published on her CD Music of Timor (Celestial Harmonies 13182-2), track 16. 
Bunga Anggrek. We have a female chorus and two male choruses. I start the notation with the female part, for convenience. The women's phrase has thirteen beats, the first men's chorus has fourteen beats, and the second men's chorus has five beats. ${ }^{8}$ All of the beats are subdivided in three. In these phrases there are no internal symmetries. We can call each of the beats one measure of rapid triple meter, in which case we have another thirty-two-bar structure. But where Bunga Anggrek divides its thirty-two bars neatly into eight four-measure phrases, this Timor song divides the same length $13+14+5$. You can hardly get more asymmetrical than that, and for that reason, since most of us are used to an even flow of four-bar phrases or something similar, this song leaves us confused, without landmarks. If you don't count every beat, you can't tell when the different choruses will start their phrases.

\section{SONG FROM TIMOR (Kabupaten Belu)}
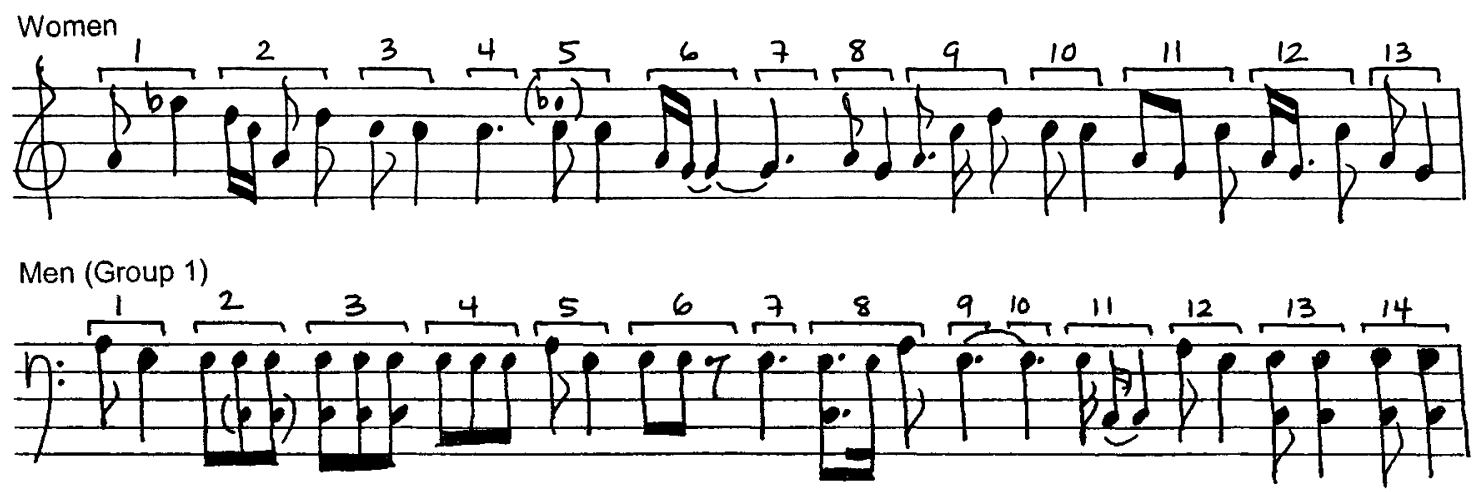

Men (Group 2)

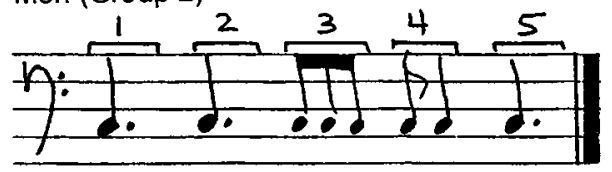

from Music of Timor recorded by $M$. Kartomi

Celestial Harmonies 13182-2

Actual pitch a minor third above notation

( $C$ here sounds as $A)$

transcribed - P.Y.

Figure 2

My point is that this song from Timor represents a very different way of organizing sound-in this case phrase structure-from what most of us think is "natural." Yet these singers are performing as though it were perfectly natural to them to sing in these unequal, asymmetrical phrases-which no doubt it is.

${ }^{8}$ It is difficult to hear when the first men's chorus ends and the second begins. An alternative analysis of the song would give the first men's chorus twelve beats and the second one seven beats. 
Here is a final example, even stranger-to most of us-than the last. It comes from the people of the Upper Jelai River in the southern part of West Kalimantan. ${ }^{9}$ It is played on seven pairs of bamboo tubes. The instruments of each pair are struck together. Five of the bamboo pairs play together in an invariable manner producing one chord if the lowest tone is $\mathrm{D}$ and another chord if the bottom tone is E. ${ }^{10}$ (Figure $3 \mathrm{a}$, below) Since the chords are invariable, I didn't need to crowd up the notation by writing them out; it was enough to give just the bottom D or E of the chord (shown in the top line of each stave in Figure 3b, with stems up). Now, I have written this out with time-signatures. Of course, the Upper Jelai musicians don't care at all about these sevens and elevens; they just play the piece. The time-signatures are simply an analytical device to help us outsiders see what is going on, and to help us recognize that after the musicians play once through this apparently irrational, incomprehensible sequence of clicks and clacks, they then do the whole thing again, in the same sequence. Here it is. Hold onto your hats.

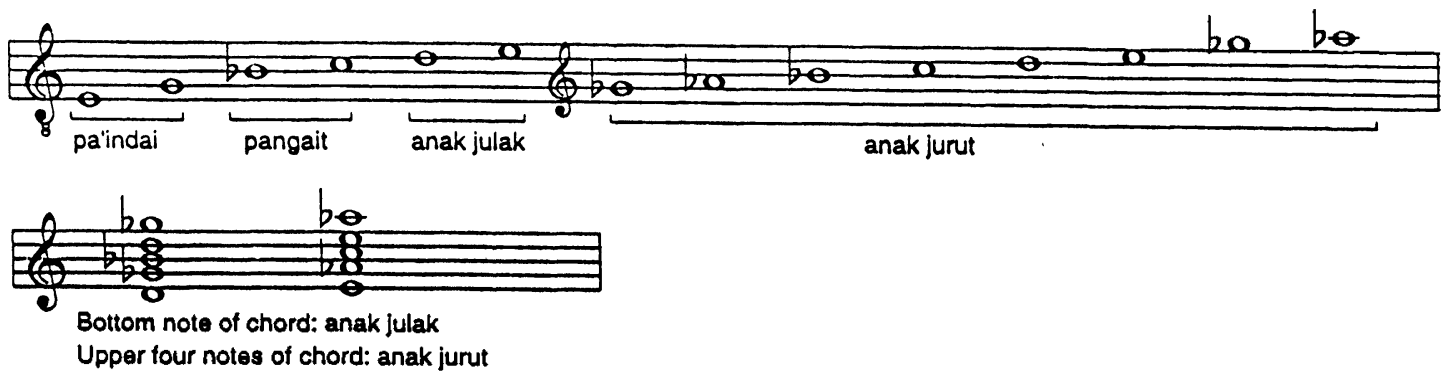

Figure 3a

I will bet that hardly anyone here finds this music easy to grasp. That is because its structure makes no sense to us-we have no experience in hearing sound organized like this. And that's my point-when we do hear this music we come face to face with a different way to organize sound from what we're used to, and that symbolizes a different way to organize experience, a different way to live.

That's what traditional music can do for us: suggest the possibility that life can be lived differently. Traditional music is inherently counterhegemonic for anyone outside the tradition: it shows that the order we take for granted is not the only one there is. I

\footnotetext{
9 The piece is an example of the genre of music called senggayung. It was recorded in 1995 and is published on Kalimantan: Dayak Ritual and Festival Music (Music of Indonesia, 17; Smithsonian Folkways SFW 40444), track 5. It is also published on the Music of Indonesia series sampler, Discover Indonesia (Smithsonian Folkways SFW 40484), track 12.

${ }^{10} \mathrm{I}$ call these tones $\mathrm{D}$ and $\mathrm{E}$, and write them that way in Figures $3 a$ and $3 \mathrm{~b}$, for my convenience. In absolute pitch they are a half-step higher: Eb and F.
} 
KALIMANTAN
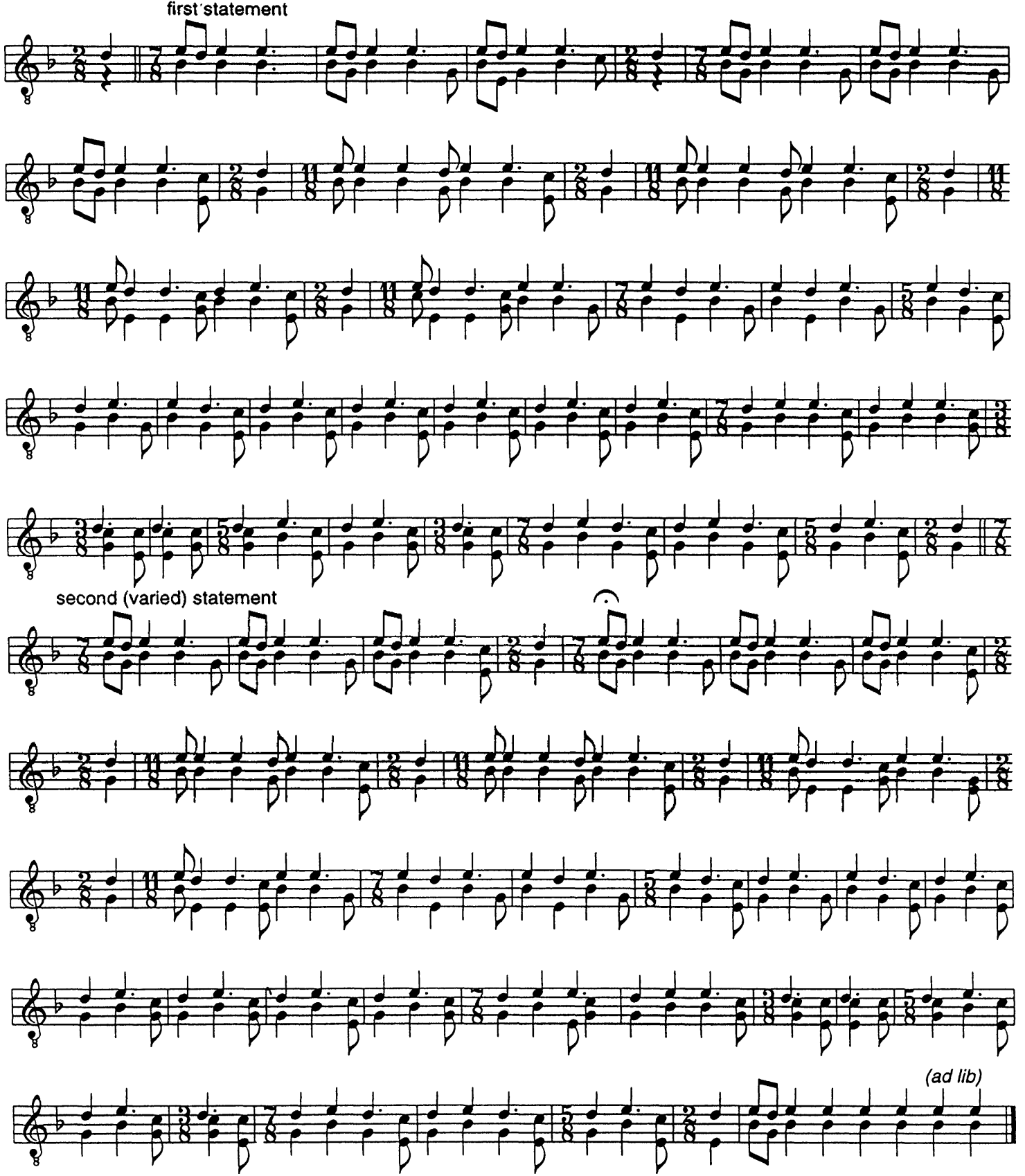

Actual pitch half-step above notation ( $E$ here sounds as $F$ )

transcribed - P.Y.
Stems down - pa'indai \& pangait

Stems up - anak julak only

(anak jurut chords can be inferred from

anak julak - see Figure 3a)

Figure $3 b$ 
believe this is crucially important information for people everywhere today. Increasingly we all have the same experiences, hear the same messages from the same media, buy the same products, are governed by the same laws, depend upon the same technology. We need to be reminded constantly of the grand history of human difference, of the diverse structures of existence. Appreciating the arts of another society does not require us to abandon our own principles, does not require us to share the religious beliefs or cultural practices of the society that produced the art. We can appreciate the work of the human imagination, the great work of design and structure, without being implicated in the specific content and context. Structuring the world, interpreting it, is a necessary human activity, and we all can learn from what the rest of us have done.

\section{Glossary: Indonesian Music Genres}

Dangdut - urban popular music of today, typically using the basic instrumentation of a rock band plus flute. Its idiom mixes rock, Indian pop, and Middle Eastern pop.

Gondang - traditional music of the Toba Batak of North Sumatra. Gondang may be played on an ensemble of tuned drums, gongs, and oboe (gondang sabangunan) or an ensemble of two plucked lutes, xylophone, oboe, and flute (gondang hasapi).

Hoho - traditional vocal music of Nias, typically sung by a male soloist and male chorus.

Kroncong -a prominent urban popular music in the years 1920-1960. Its standard instrumentation is violin, cello, guitar, two small plucked lutes (mandolin, ukulele), flute, and singer.

Macapat - unaccompanied sung poetry in Java and Bali.

Orkes gambus - a popular orchestra with strong Middle Eastern flavor. Heavy with violins and cellos, it is basically the orchestra of Egyptian popular music of Umm Kulthum's time.

Pakarena - a dance of the Makasar people of South Sulawesi, combining frenetic drumming (plus gong and oboe) with very slow dance movements.

Pop Indonesia - urban popular music of today, using mainly electrified instruments and sounding wholly European/American in musical idiom.

Qasidah Moderen - modern popular music with lyrics and performance style in keeping with Muslim precepts. In instrumentation it may vary from just a set of tambourines and frame drums to a dangdut band; its idiom resembles that of dangdut, but with more stress on the Middle Eastern elements.

Saluang (or saluang jo dendang) - music of the Minangkabau of West Sumatra: singing accompanied by the saluang flute.

Tanjidor - a European-style brass band, sometimes with Indonesian drums, gongs, and other instruments added. Some tanjidor groups play the popular Dutch and Indonesian tunes of fifty or one hundred years ago; some play music that is wholly Sundanese (West Javanese) in idiom, but transferred to the brass band instruments.

Tembang Sunda - "classical" vocal music of West Java, accompanied by plucked zithers. 

Review Essay

\section{A MuSiCAL PICTURE Of INDONESIA}

\section{Jan Mrázek}

Music of Indonesia, recorded, compiled, and annotated by Philip Yampolsky (Smithsonian Folkways and the Indonesian Society for the Performing Arts, 19911999), 20 vols. [Titles of individual volumes and more discographical information follow the essay.]

I have chosen to write about this twenty-volume series as a whole. Each volume is significant in its own way, and a reviewer of a single volume might do better justice to the particular volume. However, the series does very much form a whole, and it is the appearance of the series as a whole-rather than the release of any single volumethat is an event of such significance, it should make us pause and listen.

Size does matter, but large spaces can be used well or wasted. Philip Yampolsky, the editor, is to be applauded for being able to realize the full potential of the space given to him and to build in the space a monumental work. He made the scope of the series-the number of well-represented kinds of music from various regions of Indonesia-one of its most impressive features. It is against the background of the size and scope that one should admire the quality and quantity of scholarly work that has gone into the project, the ambitious overall concept, a certain unifying consistency of vision (or hearing, or philosophy, or emotion) behind the overall plan and behind each selection, the care with which every item has been selected and presented-each selection (and each volume for that matter) has a clear raison d'être in the larger whole-, the power and inner life in each piece of music, and the fact that the series, as a whole, makes a powerful statement.

One way to approach the series is to consider it as a monumental musical picture of Indonesia. As such, the series is not only immensely important for people interested in Indonesian music, but it also makes a great contribution to our understanding of the country.

I have spoken of a consistency of vision. But this vision does not flatten the musical landscape. On the contrary, what the overall picture shows, more than anything else, is a variety and diversity of (musical) creatures. Yampolsky writes that the series "offers a sampling of this tremendous variety." (All vols., p. 1) People often 
speak of the diversity in Indonesia; but the series succeeds in doing something more than mere reporting. As one listens to the different kinds of music, one gets an intensely physical experience of the diversity. One does not merely hear about it; one hears it. One hears how people move their bodies and breathe differently and in different meters and rhythms; one hears different voices; one hears how people shape and use material things to create particular kinds of sounds and musical structures; and, in the variety of musical structures, one perceives different ways of organizing sounds and social relationships (for collective music-making is always also that). In the music, one hears people's histories and ways of being. One could say that one gets a preconceptual experience of the diversity, yet at the same time this is part of the musical concept of the series, and it is the act of bringing the different kinds of music together that allows one to hear the variety.

I need to say more about what kind of diversity the series shows. Let me make a comparison. I am thinking of a cassette, a copy of which I got from a friend, produced in Indonesia and called Songs from Whole Indonesia (Lagu-lagu dari seluruh Indonesia). It offers, it seems to me, the New Order government's vision of Indonesia, represented by music. Rarely does one encounter this vision in such a pure form, distanced from and uncomplicated by the reality of what happens in Indonesia. The tape contains one loooooong composition. It is an uninterrupted medley of songs from all the provinces of Indonesia. What is most striking, if I can use that word, is that the whole time, for the songs from all the twenty-seven provinces, there is only one beat, one tempo, one way of singing, one musical idiom (a kind of castrated march music), one kind of feeling. The tape is thus a musical equivalent of New Order projects such as "Taman Mini 'Indonesia Indah"" ("The 'Beautiful Indonesia'-in-Miniature Park), or of certain shows on television in which, for instance, the dances from all the provinces are performed on a single stage in the same, clean, tidy, and glamorous manner. Diversity, on the tape, as in Taman Mini, is a major theme. But it is diversity tamed by a vapid unity, diversity represented only to show that things are ultimately all the same, without tensions, songs from everywhere sung all to a single beat in a single tempo, lacking a distinct character and inner life.

State's representations of Indonesia and its arts and traditions have been analyzed in scholarly literature about Indonesia, an important task because these representations are an important force in Indonesia. However, the focus on the state's representation and state's politics has led to under-representation of what happens beyond the limits of the state's control and the life, tensions, play, that persist despite it or, somehow, "beneath" or apart from governmental politics, the life and play that can be found when governmental politics change tone as they penetrate into everyday life. More recently, a number of scholars have pointed out that this trend in scholarship, by focusing on the politics of the state's representation of Indonesia and by adopting (even while criticizing) its terms (which were often adapted from colonial ethnography in the first place), reinforces the state's picture because it, too, fails to represent what is happening beyond, beneath, and in the gaps of, the state's representation. ${ }^{1}$

${ }^{1}$ For further discussion, see essays by Tony Day, René Lysloff, Andrew Weintraub, Matthew Cohen, and my Introduction, in Puppet Theater in Contemporary Indonesia: New Approaches to Performance Events, ed. 